\title{
Surfactant Replacement therapy in Preterm Infants with respiratory Distress Syndrome
}

\author{
Professor Dr. NumanNafie Hameed (MD, FRCPCH, FIBMS, MRCPCH, MAAP) ${ }^{1}$, \\ Dr. HossamSubhiTalab (MD, CABP) ${ }^{2}$ \\ ${ }^{I}$ Department Of Pediatrics, College Of Medicine, Baghdad University, Consultant Pediatrician, Children \\ Welfare Teaching Hospital, Medical City, Baghdad \\ ${ }^{2}$ Neonatal Fellow, Children Welfare Teaching Hospital, Medical City, Baghdad
}

\begin{abstract}
:
Objective: To study the neonatal morbidity and case fatality in preterm infants with respiratory distress syndrome treated with different methods of administration of surfactant replacement therapy.

Study design:This cross-sectional analytic study included 104 preterm infants, who had respiratory distress syndrome during one year period. The samplewas dividedinto prophylactic, early and late rescue groups, according to earliest time of surfactant administration.

Results:The mean gestational age was $29.7 \pm 4.5$ (range: 24 - 37) weeks, 32 infants (30.77\%) of 24 - 28 weeks, $40(38.46 \%)$ were of $28+1 / 7-32$ weeks and $32(30.77 \%)$ at $32+1 / 7-37$ weeks. Prophylactic surfactant was administered in 44 (42.3\%), early rescue in 37 (35.6\%) and late rescue in 23 (22.1\%).98 (94.2\%) received one dose of surfactant. Mechanical ventilation was applied in 78 (75\%). 93 (89.4\%) had at least one complication, sepsis was the most common in 67 (64.4\%), sepsis was significantly higher among infant who received prophylactic surfactant $(88.6 \%)(P 2=0.001)$. The highest case fatality was in infants who received prophylactic surfactant $(77.3 \%),(P=0.001$. $)$.

Conclusions: Prophylactic surfactant was administered in majority of preterm neonates with respiratory distress syndrome.Sepsis was the most common complication and was significantly higher among infant who received prophylactic surfactant, which in turn was associated with higher case fatality rate.

Keywords:Preterm infants, neonate, surfactant replacement therapy, respiratory distress syndrome, continuous positive airway pressure, mechanical ventilation.

Abbreviations: RDS: Respiratory Distress Syndrome, CPAP: Continuous Positive Airway Pressure, MV: Mechanical ventilation, GA: Gestational Age, BWT: Birth Weight, CS: Cesarean Section, NVD: Normal Vaginal delivery, NICU: Neonatal Intensive Care Unit, ETT: Endotracheal tube
\end{abstract}

\section{Introduction}

Prematurity is one of the most perplexing problems in perinatal care. Since the discovery of a surfactant deficiency as the primary etiology of hyaline membrane disease, attempts have been made to supplement Surfactant in the premature infant. ${ }^{[1]}$

Respiratory distress syndrome (RDS) is the most common serious disease affecting the newborn.As a result of the successful marriage between clinical investigation, applied and basic sciences, the mortality of RDS has dropped from about $50 \%$ to close to $5 \%$. ${ }^{[2]}$ Endogenous surfactant is a biochemical compound composed of phospholipids, neutral lipids, and proteins that forms a layer between the terminal airways/alveolar surfaces and the alveolar gas. ${ }^{[3-5]}$ In 1959, Avery and Mead published a landmark paper that correctly hypothesized that the clinical entity known as HMD was deficiency of the surface tension lowering material or surfactant. ${ }^{[4,6]}$ Surfactant replacement was established as an effective and safe therapy for immaturity-related surfactant deficiency by the early1990s.Systematic reviews of randomized, controlled trials confirmed that surfactant administration in preterm infants with established RDS reduces mortality, decreases the incidence of pulmonary air leak, and lowers the risk of chronic lung disease or death at 28 days of age ${ }^{[7,8]}$ Exogenous surfactant, used as a drug for the treatment of RDS of the newborn infant has been extensively studied over the past 15 years by means of many randomized controlled trials (RCTs). ${ }^{[9]}$

A prophylactic, or preventive surfactant strategy is defined as intubation and surfactant administration to infants at high risk of developing RDS for the primary purpose of preventing worsening RDS rather than treatment of established RDS; this has been operationalized in clinical studies as surfactant administration in the delivery room before initial resuscitation efforts or the onset of respiratory distress or most commonly, after initial resuscitation but within 10 to 30 minutes after birth. ${ }^{[10]}$ This contrasts with a rescue or treatment surfactant strategy, in which surfactant is given only to preterm infants with established RDS. Rescue surfactant is most often administered within the first 12 hours after birth; early rescue is defined as surfactant treatment within 1 to 2 hours of birth, and late rescue is defined as surfactant treatment 2 or more hours after birth. ${ }^{[9]}$

DOI: 10.9790/0853-15076136142 $\quad$ www.iosrjournals.org $\quad 136 \mid$ Page


Further research is needed to define potential limitations on the type of patients for which early surfactant with rapid extubation is appropriate (such as very premature infants $<750$ grams) and to determine the optimal threshold of severity of respiratory distress syndrome for which to intervene with transient intubation for the purpose of surfactant administration. ${ }^{[11]}$

This study aimed to study neonatal morbidity and case fatality in preterm infants with respiratory distress syndrome treated with different methods of administration of surfactant.

\section{Patients and Methods}

In this cross-sectional analytic study, data of 104 preterm infants were collected from NICUs of nursing home hospital with GA of 24-37 weeks who had RDS and who were born from the 1st of January 2014 till the 31th of December 2014. The Ethical committee of Children Welfare Teaching Hospital and Nursing home Hospital approved the study. Sixty-Eight neonates were delivered in private nursing home hospital, 19 were referred from Baghdad teaching hospital and 17 were referred from private hospitals in Baghdad.

Assessment of GA was according to Ballard score andlast menstrual period.In Ballard scoring system, estimation of gestational age by examination for physical and neurological criteria of maturity, this is accurate to \pm 2 wk. ${ }^{\{12\}}$

The 104 preterm infants were divided into three groups (prophylaxis, early rescue, and late rescue treatment groups) depending on the time of surfactant therapy for treatment of RDS.

A prophylactic or preventive surfactant strategy was defined as intubation and surfactant administration to infants at high risk of developing RDS(infants less than 30 weeks or low birth weight $<1,000 \mathrm{~g}$ ) for the primary purpose of preventing worsening RDS rather than treatment of established RDS within 10-30 minutes after birth.In a rescue or treatment surfactant strategy, the surfactant was given only to preterm infants with established RDS. Surgical cases, meconium aspiration, congenital lung diseases, or syndromes had been excluded.

The included neonates were admitted and followed in NICU, for short term outcome including morbidity and case fatality during the first 28 days of life; and observing the development of complications following replacement therapy in these study groups as sepsis, pulmonary hemorrhage, air leak, Bronchopulmonary dysplasiaetc. Anonymous data were collected included: GA, BWT, gender, mode of delivery, intubation need, surfactant therapy (type, dosage, frequency, and clinical indications).For all patients, an animal-derived Beractant (Survanta, the only type available in Iraq) minced bovine lung extract was used. The indications for surfactant therapy were according to American academy guidelines; committee on fetus and newborn, including preterm infant with clinical RDS especially in those with low (GA and BWT), radiological evidence of RDS as fine reticulogranular appearance and air bronchogram on chest $\mathrm{x}$-ray; those with high ventilator requirements as FIO2 need $>40 \%$ of inspired oxygen to maintain appropriate arterial pressure. ${ }^{\{7\}}$

The surfactant was administered after Inserting appropriate nasogastric tube that has been cut to a suitable length so as not to protrude beyond the tip of the ETT on insertion through the ETT. No positional changes were required for surfactant given in delivery room. Surfactant was delivered as a bolus as fast as it can be easily pushed through the catheter and then Continue PPV with adjustments to settings if there is bradycardia or desaturation. ${ }^{[13]}$

The first dose of surfactant was given as early as possible to the preterm infants requiring MV for RDS. The repeat dose was given 4-6 hours later if $\mathrm{FiO} 2$ is still $>0.30$ with optimal tidal volume settings for those below 32 weeks and if $\mathrm{FiO} 2>0.40$ and CXR still shows moderate to severe RDS ("white" CXR) for those infants $>32$ weeks gestational age. ${ }^{[13]}$

Infants were monitored closely after surfactant administration with a pulse oximeter and regular blood gas measurements if available. Ventilator settings were promptly decreased to reduce the risk of pneumothorax and ventilator induced lung injury. Extubation to CPAP was considered if the oxygen requirement is less than $30 \%$ and there are minimal pressure requirements. ${ }^{[13]}$

Statistical analysis: Data of the 104 RDS infants were entered and analyzed by using the statistical package for social sciences version 22, IBM, US, 2013. Descriptive statistics were presented as mean, standard deviation (SD), frequencies (No.) and proportions (\%). Chi square and Fishers exact test were used alternatively to compare frequencies. Level of significance ( $p$. value) was set at $\leq 0.05$ to be considered as significant and,$<0.001$ to be highly significant. The results and findings were introduced in tables and paragraphs by using the Microsoft Officesoftware, Words, version 2013, for with.

\section{I11. Results}

A total of 104 preterm infants with mean GA was $29.7 \pm 4.5$ (range: 24 - 37) weeks, 32 infants $(30.77 \%)$ of 24 - 28 weeks, $40(38.46 \%)$ were at $28+1 / 7-32$ weeks and $32(30.77 \%)$ at $32+1 / 7-37$ weeks. Males were 58 $(55.77 \%)$ and females were $46(44.23 \%)$ with a male to female ratio of 1.26:1.(Table CS deliverywas reported in $68(65.38 \%)$ and the NVD in $36(34.62 \%)$. Single birth was reported in $72(69.23 \%)$, twins in $21(20.19 \%)$. (Table 1) Prophylactic surfactant was administered in 44 infants (42.3\%), early rescue in 
$37(35.6 \%)$ and late rescue in $23(22.1 \%)$. Majority of the infants 98/104 (94.2\%) received one dose of surfactant and $6(5.8 \%)$ received 2 doses while none of the infants received three doses. MV was applied in 78 (75\%) and CPAP was applied in 26 infants $(25 \%)$. Nasal cannula was not applied in this study. (Table Out of the 104 RDS infants, $93(89.4 \%)$ had at least one complication and 11 infants (10.6\%) had no complications. Sepsis was the most incident complication in67 (64.4\%) followed by Nasal trauma in 18 (17.3\%), Air-leaks in 13 (12.5\%), Pulmonaryhemorrhage in 6 infants (5.8\%). PDA and BPD were less frequent in $3(2.9 \%)$ and $2(1.9 \%)$ infants, respectively. Some infants had more than one complication simultaneously.(Table

3)

Out of the 104 RDS infants, $47(45.2 \%)$ were alive and 57(54.8\%) died, giving an overall case fatalityrateof54.

Three comparisons were performed, for each complication; the first one was prophylactic vs. earlyrescue surfactant, the second was prophylactic vs. late rescue and the third between early and late rescue surfactant. The rate of sepsis was significantly higher among those infant who received prophylactic surfactant $(88.6 \%)$ as compared to early rescue $(45.9 \%),(\mathrm{P} 1=0.001)$, and the Late rescue $(\mathrm{P} 2=0.001)$ while no statistically significant difference between early and late rescue regarding the incidence of sepsis, $(\mathrm{P} 3=0.59)$. Conversely, no statistically significant difference had been found between the methods of surfactant, in other complications, in all comparison, $\mathrm{P}>0.05$.(Table 4) The highest case fatality was reported among infants who received prophylactic surfactant $(77.3 \%)$ than early $(43.2 \%),(\mathrm{P}=0.003)$, or late rescue $(30.4 \%),(\mathrm{P}=0.001)$. The fatality was higher in early than late rescue group, however, the difference between these two methods of rescue surfactant was statistically insignificant $(\mathrm{P}=0.42)$. These findings indicated that early rescue surfactant reduced fatality by $34.1 \%$ and late rescue by $46.9 \%$ than prophylactic surfactant.(Table 5)

The fatality rate had significant $(\mathrm{P}<0.05)$ inverse correlation with the GA, where 26 infants died out of the 32 infants whose GA $24-28$ weeks with the higher fatality rate of $(45.6 \%)$. The fatality rate was $35.1 \%$ among the 40 infants with GA of $28+{ }^{1 / 7}-32$ weeks and the lower fatality rate (19.3\%) was reported in those with GA of $32+{ }^{1 / 7}-37$ weeks.(Table 6)

Lower incidence of sepsis $(46.2 \%)$, air leaks $(0.0 \%)$, and pulmonary hemorrhage $(3.8 \%)$ was found in infants on the CPAP compared to $70.5 \%, 16.7 \%$ and $6.4 \%$, respectively in infants on MV. The differences were statistically significant for sepsis and air leaks $(\mathrm{P}<0.05)$, but not significant in pulmonary hemorrhage $(\mathrm{P}>0.05)$. Nasal trauma was more incident among those on CPAP (34.6\%) compared to $11.5 \%$ in those on MV ( $\mathrm{P}=0.035)$. PDA and BPD were also more incident among infants on CPAP rather than those on MV, however the differences were statistically insignificant in these two complications (P>0.05).(Tab Moreover, 5/26 infants in CPAP group (19.2\%) had no complication, compared to only $6 / 78$ in MV group (7.7\%), indicated that the complications were more incident in MV group than in CPAP group ( $\mathrm{P}=0.02)$. (Table 7)Eighteen $(69.2 \%)$ infants on CPAP were alivevs. $29(27.2 \%)$ on MV. Lower fatality rate was reported in infants on CPAP than those on MV; 8(30.8\%) vs. 49(62.8\%), respectively, (P=0.008).

\section{V. Discussion}

Previous trials of surfactant therapy in premature infants have demonstrated a survival advantage associated with prophylactic therapy as an immediate bolus, compared with the rescue treatment of established RDS. The optimal strategy for prophylactic therapy, however, remains controversial. ${ }^{[14]}$

This study included 104 preterm newborn who were admitted to NICU in one year. Forty-Four babies (42.3\%) whose GA 30weeks or weight < one kg received prophylaxis surfactant while seventy babies $(57.7 \%)$ received a rescue treatment. A number of studies have evaluated whether surfactant should be given to all babies at significant risk for developing RDS or only after the development of significant disease ${ }^{[15]}$. A study reviewed seven RCTs of prophylactic versus rescue therapy. These were all trials that used natural surfactants. Six of the RCTs enrolled babies less than 30 weeks of gestation and one enrolled babies of 29 to 32 weeks of gestation. Mortality, both before 28 days and before hospital discharge, was reduced by prophylactic surfactant treatment. This difference may be related to the referral of many infants from Baghdad hospital or other private hospital in Baghdad, sothe time of administration was delayed in many cases. Surgical cases, meconium aspiration, congenital lung diseases, or syndromes have been excluded whatever the gestational ages.

In this study,65\% of babies were delivered by $\mathrm{C} / \mathrm{S}$ and $34 \%$ by NVD, this is similar to many other studies $^{[16],[17]}$, which showed increase incidence of RDS in C/S than NVD. The results indicate that infants born by CS without labor have a higher risk for neonatal RDS than infants born vaginally or by CS after a trial of labor. ${ }^{[17]}$

When comparing between prophylaxis and rescue treatment, higher rate of sepsis and fatality rate was found in prophylaxis group than rescue, this may be due to extreme prematurity of such group, improper transport measures, bad obstetrical management, and improper strategies ofinfection control. 
Seventy- five percent of babies who received surfactant needMV and only $25 \%$ need CPAP, whileother studies advise rapid surfactant administration and extubation to CPAP or high flow nasal cannula. It is notable that infants as immature as 24 weeks' gestational age were enrolled in many of the trials. In a subgroup analysis in the SUPPORT trial, the most immature infants (born at 24 and 25 weeks' gestation) got benefit mostly from the CPAP strategy. Many extremely preterm infants can be managed with CPAPonly; early application of nasal CPAP (without surfactant administration) was successful in $50 \%$ of infants weighing $\leq 750 \mathrm{~g}$ at birth in one retrospective review. ${ }^{[18]}$ Surfactant administration can be expensive, particularly in low-resource settings. Additionally, intubation and MV may not be possible or desirable in institutions with limited resources.

CPAP providesan alternative for early respiratory support in resource-limited settings. Emerging evidence indicates that early CPAP is an effective strategy for respiratory support in extremely preterm infants. CPAP appears to be at least as safe and effective as early surfactant therapy with MV. ${ }^{[19]}$ This diversity may be due to bad clinical situation of arriving babies or bad technique in our center and bad decision making by the medical staff.

Nasal trauma as a complicationswas found in $17.3 \%$, which occur mainly in babies who were exposed to nasal prongs of CPAP for long period while in other study nasal trauma range from $40-88 \% .{ }^{[20]}$ Nasal traumas is a frequent complication of nCPAP, especially in preterm neonates, but long-term cosmetic sequelae are very rare. The above study provides a description of nasal trauma and proposes a simple staging system. [20] In an Iraq study, some degree of nasal trauma was found in babies receive nasal CPAP or weaned from ventilator to CPAP ranging from $24-44 \%$ of total babies which is slightly higher than this study results ${ }^{\text {[21]. }}$

High rate of sepsis was found mainly in prophylaxis group $88.6 \%$ and less in early rescue $45.9 \%$ and late rescue $47.8 \%$, which is statistically significant, while other secondary complications such as air leaks, pulmonary hemorrhage, and PDA are not statistically significant between the three strategies. This is not compatible with other studies which all show decrease incidence of complication with prophylaxis surfactant. ${ }^{[7]}$

Few studies have compared prophylactic surfactant with early rescue treatment, and early rescue treatment with late rescue treatment. ${ }^{[1,14,22,23]}$ Although limited, the results of such studies indicate that surfactant administered prophylactically or as soon as possible in the course of respiratory distress is more effective than late rescue surfactant at improving outcomes.

High fatality rate was found in prophylaxis group $77.3 \%, 43.2 \%$ in early and $30.4 \%$ in late rescue groups. When comparing with other studies, much less mortality rate was found as shown in Turkish study $(19 \%)^{[24]}$ and in another study with MR not exceed $12 \%{ }^{[25]}$, this may be due to smaller GA of such group, lowerBWT, severity of asphyxia and respiratory distress at birth, in addition to other undiagnosed complication such as early IVH.

In this study, the complications were more incident in MV group than in CPAP group. Low incidence of sepsis $(46.2 \%)$, air leaks $(0.0 \%)$, and pulmonary hemorrhage $(3.8 \%)$ in infants on the CPAP, compared to $70.5 \%, 16.7 \%$ and $6.4 \%$ respectively in infants on MV. Some studies show CPAP exposure of premature infants with RDS is protective against chronic lung disease, intraventricular hemorrhage and sepsis compared to MV. No differences were observed regarding air leak syndrome or death. ${ }^{[26]}$, others show CPAP is not fully safe and can still result in serious complications if not managed properly. [ $\left.{ }^{27}\right]$

\section{Conclusions}

Prophylactic surfactant was administered in majority of preterm infants with RDS.Most of studied neonates received one dose of surfactant, $\mathrm{MV}$ as respiratory support rather than the CPAP, and had at least one complication.Sepsis was the most common complication and was significantly higher among infant who received prophylactic surfactant. Lower rate of sepsis was found in infants on the CPAP than on MV.The case fatality rate was $54.8 \%$. The highest was reported among infants who received prophylactic surfactant and low fatality rate in infants on CPAP than those on MV.

This study recommends that Infants who are at a significant risk of RDS may need to be stabilized first and then given the surfactant andrapid weaning to CPAP and also improve infection control in NICU.

Acknowledgement: We would like to express our grateful thanks to Dr. Sabah Al-Maamuri for reviewing this article.

Conflict of interest: The authors report no conflict of interest. The authors alone are responsible for the content and writing of this article. 


\section{References}

[1]. Miller EP, Armstrong CL. Surfactant Replacement Therapy Innovative Care for the Premature Infant. Journal of Obstetric, Gynecologic, \& Neonatal Nursing 1990 Jan.;19(1):14-17.

[2]. Hallman M,Saarela T. Respiratory Distress Syndrome: Predisposing Factors, Pathophysiology and Diagnosis.In: Buonocore G, Bracci R, Weindling M(Editors), Neonatology, A practical approach to neonatal management, Chap. 62, Springer, Italy, 2012: PP 441-454.

[3]. Jobe A. Surfactant treatment for respiratory distress syndrome. Respir Care 1986; 31(6): 467-476.

[4]. Avery ME, Mead J. Surface properties in relation to atelectasis and hyaline membrane disease. AMA J Dis Child 1959May; 97(5, Part1):517-523.

[5]. Berry DD. Neonatology in the 1990's: surfactant replacement therapy becomes a reality. ClinPediatr (Phila) 1991; 30(3):167-172

[6]. Hallman M, and Gluck L. Phosphatidylglycerol in lung surfactant. Possible modifier of surfactant function. J Lipid Res. 1976; $17: 257-62$.

[7]. Engle WA and the Committee on Fetus and Newborn. Surfactant replacement therapy for respiratory distress in the preterm and term neonate. Pediatrics. 2008; 121(2):419-432. DOI: 10.1542/peds.2007-3283

[8]. Soll RF. Synthetic surfactant for respiratory distress syndrome in preterm infants. Cochrane Database Syst Rev. 2000 ; 2):CD001149

[9]. Bahadue FL, Soll R. Early versus delayed selective surfactant treatment for neonatal respiratory distress syndrome. Cochrane Database Syst Rev. 2012Nov14; 11:CD001456.

[10]. Polin RA, Carlo WA and committee on fetus and newborn.Surfactant Replacement Therapy for Preterm and Term Neonates with Respiratory Distress.Pediatrics 2014; 133; 156; originally published online December 30, 2013; DOI: 10.1542/peds.2013-3443.

[11]. Escobedo MB. Gunkel JH. Kennedy KA. Shattuck KE. Sanchez PJ. Seidner S. Texas Neonatal Research Group. Early surfactant for neonates with mild to moderate respiratory distress syndrome: a multicenter, randomized trial. Journal of Pediatrics 2004;144:804-8

[12]. Ballard JL, Khoury JC, Wedig K, et al: New Ballard Score. J Pediatr 1991Sep; 119:417-423.

[13]. Imam H, Phak NH, Thomas T. Pediatric protocols For Malaysian Hospitals,3rdEdition2012,chapter15,page91-92, http://www.mpaweb.org.my/file_dir/6549703650eae1487f6fb.pdf

[14]. Kendig JW, Ryan RM, SinkinRA,Maniscalco WM, NotterRH,Guillet R, et al. Comparison of two strategies for Surfactant prophylaxis in very prematureinfants: a multicenter randomized trial. Pediatrics 1998Jun; 101(6):1006 -1012

[15]. Soll RF, Morley CJ. Prophylactic versus selective use of surfactant in preventing morbidity and mortality in preterm infants .Cochrane Database syst Rev.2001;(2):CD000510

[16]. Jaina NJ, Krusea LK, Demissieb K, Khandelwalc M. Impact of mode of delivery on neonatal complications: Trends between 1997 and 2005.The Journal of Maternal-Fetal \&NeonatalMedicine2009:22(6).http://www.tandfonline.com/doi/abs/10.1080/14767050902769982

[17]. CuretLB, ZachmanRD, Rao AV,PooleWK, MorrisonJ, BurkettG. Effect ofmode of delivery on incidence of respiratory distress syndrome.Int J Gynaecol Obstet. 1988 Oct;27(2):165-170

[18]. 18.Ammari A, Suri M, Milisavljevic V, et al. Variables associated with the early failureof nasal CPAP in very low birth weight infants. J Pediatr 2005; 147(3):341-347

[19]. Pfister RH, Soll RF. Initial respiratory support of preterm infants: the role of CPAP, The INSURE method, and noninvasive ventilation.ClinPerinatol. 2012;39(3):459-481

[20]. Fischer C. Bertelle V. Hohlfeld J. et al. Nasal trauma due to continuous positiveairway pressure in neonates; Arch Dis Child Fetal Neonatal Ed 2010 Nov;95(6):F447-51.doi: 10.1136/adc.2009.179416. Epub 2010 Jun 28.

[21]. Hameed NN,RaieesYR.Continuous Positive Airway Pressure and Nasal Trauma inNeonates: a descriptive prospective study.IOSRJDMS 2015 Nov.;14(11): 110-116

[22]. Yost CC, Soll RF. Early versus delayed selective surfactant treatment forneonatal respiratory distress syndrome. Cochrane Database Syst Rev.2000;(2):CD001456

[23]. Gortner L, Wauer RR, Hammer H, et al. Early versus late surfactant treatmentinpreterm infants of 27 to 32 weeks' gestational age: a multicenterControlled clinical trial. Pediatrics 1998; 102(5):1153-1160

[24]. Sürmeli-Onay O, Korkmaz A, Yigit S, YurdakökM; Surfactant therapy in latePreterminfants: respiratory distress syndrome and beyond; The Turkish Journal ofPediatrics 2012; 54: 239-246

[25]. RamanathanR: Surfactant therapy in preterm infants with respiratory distressSyndrome and in near-term or term newborns with acute RDS; Journal ofPerinatology 2006; 26: 551-556

[26]. Pérez LA, González DM, Álvarez KM, Díaz-Martínez LA; Nasal CPAP versus Mechanicalventilation in 28 to 32 -week preterm infants with earlySurfactant administration.Biomedica. 2014 Oct-Dec; 34(4):612-23, doi: 10.1590/S0120-41572014000400015.;

[27]. Garg S,SinhaS: Non-invasive Ventilation in Premature Infants: Based on Evidence OrHabit.JClinNeonatol. 2013 Oct-Dec; 2(4): 155-159

Table 1: Demographic characteristics of the studied group $(\mathrm{N}=104)$ 
Surfactant Replacement therapy In Preterm Infants with respiratory Distress Syndrome

\begin{tabular}{|l|l|l|l|}
\hline Variable & category & No. of patients & $\mathbf{\%}$ \\
\hline Gestational age (wk) & $24-28$ & 32 & 30.77 \\
\hline & $28^{+1 / 7}-32$ & 40 & 38.46 \\
\hline & $32^{+1 / 7}-37$ & 32 & 30.77 \\
\hline & Mean \pm SD & $29.7 \pm 4.5$ & - \\
\hline & Range & $24-37$ & 55.77 \\
\hline Gender & Male & 58 & 44.23 \\
\hline Mode of delivery & Female & 46 & 65.38 \\
\hline & C/S & 68 & 34.62 \\
\hline Number of birth & NVD & 36 & 69.23 \\
\hline & Single & 72 & 20.19 \\
\hline & Twin & 21 & 9.62 \\
\hline & Triplets & 10 & 0.96 \\
\hline SD; standard deviation of the mean, & wk; $\boldsymbol{w e e k}$ & 1 & \\
\hline
\end{tabular}

Table 2: Distribution of clinical data of the studied group $(\mathrm{N}=104)$

\begin{tabular}{|c|c|c|c|c|c|c|c|c|c|}
\hline \multirow[t]{2}{*}{ Complication } & \multicolumn{2}{|c|}{$\begin{array}{r}\text { Prophylactic } \\
(n=44)\end{array}$} & \multicolumn{2}{|c|}{$\begin{array}{lr}\text { Early } & \begin{array}{r}\text { Rescue } \\
(\mathbf{n}=37)\end{array}\end{array}$} & \multicolumn{2}{|c|}{$\begin{array}{r}\text { Late Rescue } \\
(n=23)\end{array}$} & \multirow[b]{2}{*}{$P 1$} & \multirow[b]{2}{*}{$P 2$} & \multirow[b]{2}{*}{$P 3$} \\
\hline & No. & $\%$ & No. & $\%$ & No. & $\%$ & & & \\
\hline Sepsis & 39 & 88.6 & 17 & 45.9 & 11 & 47.8 & 0.001* & 0.001* & 0.59 \\
\hline Nasal trauma & 6 & 13.6 & 7 & 18.9 & 5 & 21.7 & 0.56 & 0.49 & 0.52 \\
\hline Air leaks & 4 & 9.1 & 5 & 13.5 & 4 & 17.4 & 0.73 & 0.43 & 0.72 \\
\hline $\begin{array}{r}\text { Pulmonary } \\
\text { H. }\end{array}$ & 3 & 6.8 & 2 & 5.4 & 1 & 4.3 & 0.79 & 0.57 & 0.67 \\
\hline PDA & 0 & 0.0 & 1 & 2.7 & 2 & 8.7 & 0.46 & 0.11 & 0.55 \\
\hline
\end{tabular}

Table 3: Distribution of complications among the 104 infants

\begin{tabular}{|l|l|l|l|}
\hline & Complication* & No. & $\%$ \\
\hline \multirow{3}{*}{} & Sepsis & 67 & 64.4 \\
\cline { 2 - 4 } & Nasal trauma & 18 & 17.3 \\
\cline { 2 - 4 } & Air-leaks & 13 & 12.5 \\
\cline { 2 - 4 } & Pulmonary hemorrhage & 6 & 5.8 \\
\cline { 2 - 4 } & PDA & 3 & 2.9 \\
\cline { 2 - 4 } & BPD & 2 & 1.9 \\
\hline \multirow{2}{*}{ No complications } & 11 & 10.6 \\
\hline & * Some patients had more than one complication \\
\hline
\end{tabular}

Table 4: Relationship between complications and method of surfactant administration

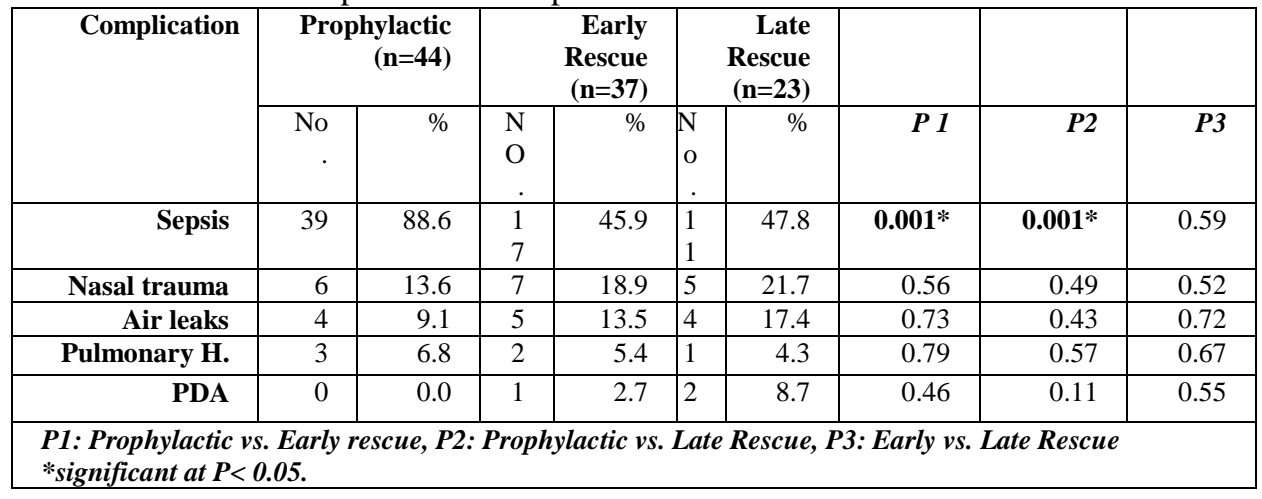


Table 5: Relationship between outcome and method of surfactant administration

\begin{tabular}{|c|c|c|c|c|c|c|c|c|c|}
\hline & & & & & & & $P 1$ & $P 2$ & $P 3$ \\
\hline \multirow[t]{2}{*}{ Outcome } & \multicolumn{2}{|c|}{$\begin{array}{r}\text { Prophylactic } \\
(\mathrm{n}=44)\end{array}$} & Early & $\begin{array}{r}\text { Rescue } \\
(\mathrm{n}=37)\end{array}$ & Late & $\begin{array}{l}\text { Rescue } \\
(n=23)\end{array}$ & & & \\
\hline & No. & $\%$ & No. & $\%$ & No. & $\%$ & \multirow[t]{3}{*}{$\mathrm{0.003}^{*}$} & \multirow[t]{3}{*}{ 0.001* } & \multirow[t]{3}{*}{0.42} \\
\hline Alive & 10 & 22.7 & 21 & 56.8 & 16 & 69.6 & & & \\
\hline Dead & 34 & 77.3 & 16 & 43.2 & 7 & 30.4 & & & \\
\hline
\end{tabular}

P1: Prophylactic vs. Early rescue, P2: Prophylactic vs. Late Rescue, P3: Early vs. Late Rescue * significant

Table 6: Relationship between outcome and gestational age

\begin{tabular}{|c|c|c|c|c|c|}
\hline \multirow{3}{*}{$\begin{array}{l}\text { Gestational age } \\
\text { (week) }\end{array}$} & \multicolumn{4}{|c|}{ Outcome } & \multirow[t]{3}{*}{$P$} \\
\hline & \multicolumn{2}{|r|}{ Alive } & \multicolumn{2}{|r|}{ Dead } & \\
\hline & No. & $\%$ & No. & $\%$ & \\
\hline $24-28$ & 6 & 12.8 & 26 & 45.6 & 0.001* \\
\hline $28+{ }^{1 / 7}-32$ & 20 & 42.6 & 20 & 35.1 & \\
\hline $32+{ }^{1 / 7}-37$ & 21 & 44.7 & 11 & 19.3 & \\
\hline Total & 47 & 100.0 & 57 & 100.0 & \\
\hline
\end{tabular}

Table 7: Relationship between Ventilation mode and complications

\begin{tabular}{|c|c|c|c|c|c|}
\hline \multirow[t]{3}{*}{ Complications } & \multicolumn{4}{|c|}{ Ventilation mode } & \multirow[t]{3}{*}{$P$} \\
\hline & \multicolumn{2}{|c|}{ CPAP $(n=26)$} & \multicolumn{2}{|c|}{ M.V. $(n=78)$} & \\
\hline & No. & $\%$ & No. & $\%$ & \\
\hline Sepsis & 12 & 46.2 & 55 & 70.5 & $0.033 *$ \\
\hline Nasal trauma & 9 & 34.6 & 9 & 11.5 & $0.014 *$ \\
\hline Air leaks & 0 & 0.0 & 13 & 16.7 & 0.035* \\
\hline Pulmonary hemorrhage & 1 & 3.8 & 5 & 6.4 & 0.69 \\
\hline PDA & 1 & 3.8 & 2 & 2.6 & 1.0 \\
\hline BPD & 2 & 7.7 & 0 & 0.0 & 0.06 \\
\hline No complications & 5 & 19.2 & 6 & 7.7 & $0.02 *$ \\
\hline
\end{tabular}

